\title{
Parâmetros de bioquímica sérica de machos, fêmeas e filhotes de Araras canindé (Ara ararauna) saudáveis mantidas em cativeiro comercial
}

\author{
Serum biochemical parameters of healthy male, female and young blue-and-yellow macaws \\ (Ara ararauna) bred in captivity
}

\author{
Stella de Faria Valle ${ }^{\mathrm{I}^{*}}$ Mariângela da Costa Allgayer ${ }^{\mathrm{II}}$ Rosecler Alves Pereira' ${ }^{\mathrm{III}}$ \\ Leonardo José Gil Barcellos ${ }^{I}$ Nicole Regina Capacchi Hlavac ${ }^{I}$ \\ Raqueli Teresinha França ${ }^{\mathrm{I}}$ Marcelo Lauxen Locatelli ${ }^{\mathrm{I}}$
}

\section{RESUMO}

O Brasil possui um considerável número de espécies de psitacídeos catalogados, perfazendo cerca de 80 espécies, sendo que as Araras canindé (Ara ararauna), uma das maiores representantes dessa ordem, podem ser encontradas em florestas nas diversas regiões brasileiras. $O$ Instituto Brasileiro do Meio Ambiente e dos Recursos Naturais Renováveis (IBAMA) normalizou a comercialização de animais da fauna silvestre provenientes de criadouros $e$ conseqüentemente ocorreu um aumento do número destes animais como de estimação. Atualmente, há pouco conhecimento sobre os parâmetros clínicos e laboratoriais de espécies silvestres em cativeiro. O presente trabalho teve como objetivo determinar parâmetros de bioquímica sangüínea de Araras canindé (Ara ararauna) saudáveis de sexo e faixa etária distintas mantidas em um criatório comercial com alimentação $e$ manejo controlados e padronizados. Foram colhidas amostras de sangue de 35 araras canindé (11 filhotes e 24 adultos) e remetidas ao Laboratório de Análises Clínicas Veterinárias da Universidade de Passo Fundo (UPF) para determinação dos seguintes indicadores bioquímicos: ácido úrico (AU), albumina (ALB), aspartato aminotransferase (AST), cálcio (Ca), colesterol (Col), creatina quinase (CK), fosfatase alcalina (FA), fósforo inorgânico (Pi), frutosamina (Fru), gama glutamil transferase (GGT), proteínas totais (PT) e uréia (UR). Entre as aves adultas, foram encontradas diferenças significativas nos valores de CK (superior nos machos), Ca e $A U$ (superiores nas fêmeas). Entre aves adultas e filhotes foram constatadas diferenças significativas nos valores de AU, Ca, ALB, COL, FA, Pi e FRU. A maioria das alterações detectadas pode ser relacionada à diferença na dieta fornecida e à condição fisiológica de cada categoria de aves. Os dados obtidos podem ser utilizados como parâmetros de referência para as araras canindé brasileiras.

Palavras-chave: Ara ararauna, bioquímica sangüínea, cativeiro.

\section{ABSTRACT}

Several psittacines have been cataloged in Brazil, totaling nearly 80 species. The blue-and-yellow macaw (Ara ararauna), the most representative species of the Psittaciformes order, lives in the forest areas of different Brazilian regions. IBAMA, Brazilian environmental protection agency, has authorized the trade of wild animals raised in breeding facilities; consequently, their use as household pets has increased ever since. Currently, too little is known about clinical and laboratory parameters of wild species bred in captivity. The aim of the present study was to determine the serum biochemical parameters of healthy blue-and-yellow macaws (Ara ararauna) of different sexes and ages reared in a commercial breeding facility under controlled and standardized feeding and management practices. Blood samples were collected from 35 blue-and-yellow macaws (11 fledglings and 24 adults) and sent to the Laboratory of Veterinary Clinical Pathology of Universidade de Passo Fundo (UPF) for measurement of the following biochemical parameters: uric acid (UA), albumin (Alb), aspartate aminotransferase (AST), calcium (Ca), cholesterol (Chol), creatine kinase (CK), alkaline phosphatase (AP), inorganic phosphorus (iP), fructosamine (Fru), gammaglutamyl transferase (GGT), total protein (TP) and urea nitrogen (Ur). There were significant differences among adult macaws with regard to CK levels (higher in males) and to Ca and UA levels (higher in females). Differences were noted among adults and fledglings with respect to UA, Ca, Alb, Chol, AP, iP and Fru. Most of the findings can be ascribed to the different feeding regimens and ages of the birds analyzed. The data obtained herein can be used as reference parameters for Brazilian blueand-yellow macaws.

Key words: Ara ararauna, serum biochemistry, captivity.

\footnotetext{
ICurso de Medicina Veterinária, Hospital Veterinário, Universidade de Passo Fundo (UPF), Campus I, CP 611, 99001-970, Passo Fundo, RS, Brasil. E-mail: stellavalle@upf.br.*Autor para correspondência.

"Faculdade de Medicina Veterinária, Universidade Luterana do Brasil (ULBRA), Canoas, RS, Brasil.

IIIPrograma de Pós-graduação em Ciências Veterinárias, Universidade Federal do Rio Grande do Sul (UFRGS), Porto Alegre, RS, Brasil.
} 


\section{INTRODUÇÃO}

A ordem dos Psitaciformes é classificada, em três grandes famílias: a Loridae (lóris), a Cacatuidae (cacatuas) e a Psittacidae (papagaios, araras, periquitos, jandáias e maracanãs) (SICK, 1997). As florestas brasileiras abrigam os maiores representantes dos psitacídeos: as araras, que podem ser classificadas em araras azuis (Anadorhynchus hyacinthinus, A. leari e A.glaucus), araras vermelhas (Ara macao e Ara choloptera) e arara canindé (Ara ararauna) (COLLAR, 1997; SICK, 1997).

Não há um censo preciso sobre o número de espécies silvestres mantidas ilegalmente como animais de estimação no Brasil. Através das portarias 117 e 118 de 15 de outubro de 1997, o IBAMA regularizou a criação de espécies silvestres nativas e a comercialização de animais vivos, promovendo um incentivo à criação de aves em cativeiro. Atualmente tem-se observado uma elevada casuística clínica de aves silvestres acarretando um grau maior de estudos clínicos (observação pessoal). O diagnóstico laboratorial de enfermidades que acometem aves de cativeiro é prejudicado por três motivos: a dificuldade de coleta das amostras, a técnica laboratorial para pequenos volumes e a falta de valores de referência regionais para comparação. Quanto a esse último, os dados disponíveis atualmente são originários de estudos realizados no exterior, onde o clima e o manejo divergem, na maioria das vezes, daqueles do nosso meio. A escassez de dados clínicos, epidemiológicos e exames complementares limita o diagnóstico de doenças metabólicas e/ou nutricionais em espécies em cativeiro (GODOY, 2001).

Embora a utilização de exames laboratoriais para complementar o diagnóstico apresente uma limitada aplicabilidade para aves individuais (OGLESBEE, 1998), o conhecimento das alterações hematológicas e bioquímicas de aves em cativeiro pode servir como modelo para o estudo das respostas dos animais na natureza frente a um determinado desafio, bem como facilitar o diagnóstico de enfermidades. $\mathrm{Na}$ maioria das vezes, as doenças de animais cativos são comparáveis àquelas observadas em vida livre e, portanto, determinados programas de conservação ambiental podem ser beneficiados com esses dados (MUNSON \& COOK, 1993; POLO et al., 1998).

A determinação dos parâmetros bioquímicos no sangue é uma ferramenta para auxiliar o diagnóstico de doenças metabólicas, definir o perfil nutricional de uma população homogênea e permitir uma avaliação clínica mais aprofundada de indivíduos. De uma maneira geral, para aves, sugere-se a determinação de parâmetros de função renal como o ácido úrico; de indicadores do metabolismo protéico como as proteínas totais, uréia e albumina; indicadores do metabolismo energético como o colesterol e a glicose plasmática; indicador de glicemia e de estresse (PINHEIRO et al., 2003) como a frutosamina; minerais como cálcio e fósforo; e indicadores de lesão hepática como a AST e GGT e de lesão muscular, CK.

Os objetivos do presente trabalho foram: i) determinar valores de referência para indicadores bioquímicos em Araras canindé (Ara ararauna) mantidas em cativeiro com manejo controlado e ii) relacionar a variação dos parâmetros entre machos, fêmeas adultos e animais jovens com intuito de verificar as variações entre diferentes categorias fisiológicas.

\section{MATERIAL E MÉTODOS}

Animais amostrados

Foram coletadas amostras de sangue de 11 exemplares jovens de araras canindé (Ara ararauna) nascidas entre 03/2003 e 06/2003 (seis machos e cinco fêmeas) e de 24 araras canindé adultas com idades entre três e quatro anos (12 machos e 12 fêmeas), oriundas do criadouro comercial Asas do Brasil (Campo Bom RS). Após exame clínico completo, os animais foram divididos em três grupos: machos adultos, fêmeas adultas e animais jovens. Os filhotes permaneciam agrupados em recintos coletivos enquanto os casais de adultos permaneciam em recintos individuais. Todos os animais jovens nasceram no criadouro e alguns exemplares adultos eram oriundos de apreensão. Foram incluídos nesse trabalho apenas animais clinicamente saudáveis.

As aves eram alimentadas ad libitum com uma dieta composta de $60 \%$ de ração comercial, 30\% de frutas variadas e $10 \%$ de semente de girassol (Helianthus sp.). As aves adultas recebiam maior quantidade de sementes de girassol, enquanto os filhotes recebiam acréscimo de 1/3 na ração comercial.

\section{Colheita e manipulação das amostras de sangue}

Para a colheita das amostras, as aves foram contidas manualmente e sedadas com gás Isoflurane a 5\% para indução e 3\% para manutenção, por meio de máscara (OGLESBEE, 1998; FUDGE, 2000a). Foram obtidos $5 \mathrm{ml}$ de sangue através da punção da veia ulnar na superfície ventral da articulação umerorradioulnar, como indicam MARTINEZ (2003) e OGLESBEE (1998) em aves acima de $100 \mathrm{~g}$. As amostras foram armazenadas em tubos Vacutainer sem anticoagulante e refrigeradas para o transporte. No Laboratório de Análises Clínicas Veterinárias da Universidade Luterana do Brasil 
(ULBRA) as amostras foram centrifugadas para separação do soro e armazenadas a $-20^{\circ} \mathrm{C}$ por 15 dias até as análises bioquímicas no Laboratório de Análises Clínicas da Faculdade de Agronomia e Medicina Veterinária da Universidade de Passo Fundo (FAMV$\mathrm{UPF}$ ).

Determinação dos parâmetros bioquímicos

Os indicadores bioquímicos foram determinados através do uso de "kits" analíticos comerciais (Labtest Diagnóstica, Lagoa Santa, MG) em um analisador bioquímico semi-automático (Labquest - LABTEST Diagnóstica) com exceção da frutosamina, cujas absorbâncias foram determinadas em um espectrofotômetro manual (FEMTO Espectrofotômetro 432).

Através da metodologia colorimétrica de ponto final, foram determinados os seguintes parâmetros bioquímicos: proteínas totais (biureto), albumina (verde de bromocresol), ácido úrico (uricase), cálcio (cresolftaleína complexona), colesterol total (colesterol oxidase), fósforo inorgânico (fosfomolibdato), frutosamina (azul de nitrotetrazólio) e uréia (urease-GLDH). Através de métodos cinéticos, foram analisados aspartato aminotransferase (de acordo com recomendação da "International Federation of Clinical Chemistry” - IFCC), fosfatase alcalina (hidrólise da p-nitrofenil fosfato em meio alcalino), gama glutamil transferase (hidrólise da gama glutamil pnitroanilina) e creatina quinase (de acordo com recomendação da IFCC).

Análise estatística

A avaliação estatística de cada parâmetro foi obtida através de teste não-paramétrico (KruskallWallis) no programa Instat Prisma cinco (para Windows). Para constatação de diferenças entre as medianas, foi aplicado o teste de Mann-Whitney com significância de $(\mathrm{P}<0,05)$. Além da média e desvio padrão foi determinado intervalo de confiança (com significância de 95\%) de cada parâmetro.

\section{RESULTADOS E DISCUSSÃO}

$\mathrm{Na}$ literatura nacional, as informações que dizem respeito à mensuração de parâmetros bioquímicos em aves de cativeiro são escassas e, por isso, encontrou-se dificuldades na comparação dos resultados obtidos. Estudos semelhantes foram realizados por POLO et al. (1998), que mensuraram alguns indicadores bioquímicos em amostras individuais e em "pool” de amostras de 35 psitacídeos cativos, entre eles, a Ara ararauna. HARR (2002) avaliou aspectos hematológicos, bioquímicos e de urinálise em aves de companhia, porém, foi estudada apenas a espécie Ara sp. Por serem estudos mais próximos, os valores apresentados no presente trabalho foram comparados aos valores por estes autores.

Entre animais adultos (Tabela 1), os valores de CK foram superiores $(\mathrm{P}<0,05)$ nos machos $(175,95 \pm$ $\left.38,30 \mathrm{UI} \mathrm{L}^{-1}\right)$ em relação às fêmeas $\left(136,72 \pm 38,10 \mathrm{UI} \mathrm{L}^{-1}\right)$. POLO et al. (1998) não constataram diferença estatística significativa em nenhum dos parâmetros analisados em machos e fêmeas. Para a CK, indicadora de lesões musculares recentes, não há estudos que apontem valores superiores em aves do sexo masculino quando comparado às fêmeas. A diferença encontrada no presente estudo pode estar relacionada à maior massa muscular observada em machos psitacídeos quando comparado às fêmeas. LUMEIJ (1997) relaciona que aves podem apresentar elevação de CK após a contenção e que, quanto maior a massa muscular, maior será a atividade dessa enzima no soro.

Os valores de Ca $\left(9,65 \pm 0,98 \mathrm{mg} \mathrm{dl}^{-1}\right)$ e AU $\left(3,07 \pm 1,11 \mathrm{mg} \mathrm{dl}^{-1}\right)$ foram significativamente superiores em fêmeas quando comparados aos machos (9,25 \pm $0,53 \mathrm{mg} \mathrm{dl}^{-1}$ e $2,5 \pm 0,91$ respectivamente). A superioridade dos valores de Ca nas fêmeas está relacionada aos hormônios sexuais femininos que influenciam a hidroxilação da 25-hidroxivitamina D no rim antes da postura (CAMPBELL, 2004). Não foram determinados os motivos para justificar a diferença nos níveis de ácido úrico entre machos e fêmeas.

Comparando os resultados com as médias encontradas por POLO et al. (1998), foi observado que os valores de FAS e AST de ambos os sexos e UR, nas fêmeas, foram superiores aos encontrados pelo autor. Enquanto isso, os valores de Pi e ALB foram inferiores. Os valores superiores das enzimas no soro das aves estudadas podem estar relacionados à diferença na metodologia de análise, coleta e armazenamento e a meia-vida. A variação de Pi, ALB e UR, além da técnica usada pelos autores, pode estar relacionada à diferença da dieta fornecida em ambos os casos e à diferença entre espécies.

Entre aves adultas e filhotes (Tabela 2), foram observadas diferenças estatísticas significativas entre $\mathrm{AU}(\mathrm{P}=0,001), \mathrm{ALB}(\mathrm{P}=0,001), \mathrm{Ca}(\mathrm{P}=0,05), \mathrm{COL}(\mathrm{P}=0,05)$, FAS $(\mathrm{P}=0,05), \mathrm{Pi}(\mathrm{P}=0,001)$ e FRU $(\mathrm{P}=0,0001)$. Aelevação da média de ácido úrico em aves jovens $(4,85 \pm 1,97 \mathrm{mg}$ $\mathrm{dl}^{-1}$ ) pode estar relacionada ao consumo de uma dieta com elevada concentração de proteína (PHALEN, 2000). O mesmo pode estar ocorrendo com a albumina sérica que apresentou valores discretamente superiores em aves jovens $\left(1,62 \pm 0,09 \mathrm{~g} \mathrm{dl}^{-1}\right)$ em relação aos animais 
Tabela 1 - Parâmetros de bioquímica sangüínea de Araras canindé (Ara ararauna) fêmeas e machos adultos mantidos em cativeiro comercial (Criadouro Asas do Brasil).

\begin{tabular}{|c|c|c|c|c|}
\hline \multirow{2}{*}{ Parâmetros bioquímicos } & \multirow{2}{*}{$\mathrm{n}$} & \multicolumn{2}{|c|}{ Intervalo de confiança (95\%) } & \multirow{2}{*}{ Teste M-W } \\
\hline & & Fêmeas adultas & Machos adultos & \\
\hline Ácido úrico $\left(\mathrm{mg} \mathrm{dl}^{-1}\right)$ & 12 & $2,4-3,8$ & $1,9-3,1$ & $\mathrm{P}<0,05$ \\
\hline Albumina ( $\left.\mathrm{g} \mathrm{dl}^{-1}\right)$ & 12 & $1,2-1,5$ & $1,3-1,4$ & NS \\
\hline $\operatorname{AST}\left(\mathrm{UI} \mathrm{L}^{-1}\right)$ & 12 & $105,1-130,8$ & $108,7-138,6$ & NS \\
\hline Cálcio (mg dl $\left.{ }^{-1}\right)$ & 12 & $9,0-10,3$ & $8,9-9,6$ & $\mathrm{P}<0,05$ \\
\hline Colesterol (mg dl ${ }^{-1}$ ) & 12 & $177,8-230,2$ & $177,5-216,9$ & NS \\
\hline $\mathrm{CK}\left(\mathrm{UI} \mathrm{L}^{-1}\right)$ & 12 & $112,5-160,9$ & $151,6-200,3$ & $\mathrm{P}<0,05$ \\
\hline Fosfatase alcalina (UI L ${ }^{-1}$ ) & 12 & $186,7-411,0$ & $185,6-387,2$ & NS \\
\hline Fósforo $\left(\mathrm{mg} \mathrm{dl}^{-1}\right)$ & 12 & $4,9-6,2$ & $5,1-6,4$ & NS \\
\hline Frutosamina & 12 & $1,1-1,3$ & $1,0-1,2$ & NS \\
\hline GGT $\left(\mathrm{UI} \mathrm{L}^{-1}\right)$ & 12 & $5,4-8,7$ & $6,3-9,5$ & NS \\
\hline Proteínas totais $\left(\mathrm{g} \mathrm{dl}^{-1}\right)$ & 12 & $3,3-3,9$ & $3,4-4,0$ & NS \\
\hline Uréia $\left(\mathrm{mg} \mathrm{dl}^{-1}\right)$ & 12 & $5,0-7,6$ & $4,5-6,1$ & NS \\
\hline
\end{tabular}

NS= não significativo, Teste M-W= teste Mann-Whitney.

adultos $\left(1,37 \pm 0,18 \mathrm{~g} \mathrm{dl}^{-1}\right)$. FUDGE (2000b) relata que o melhor método de avaliação laboratorial da albumina é por eletroforese de proteínas séricas e, por esse motivo, os valores foram inferiores aos apresentados por POLO et al. (1998).

Embora a elevação da FAS ocorra mais comumente em animais jovens, foi constatado, no presente estudo, que os valores de FAS foram superiores em aves adultas $\left(292,64 \pm 64 \mathrm{UI} \mathrm{L}^{-1}\right)$ quando comparada às jovens $\left(159,76 \pm 49,57 \mathrm{UI} \mathrm{L}^{-1}\right)$. A elevação da atividade dessa enzima está relacionada, em animais jovens, à atividade osteoblástica e a mudanças ósseas associadas ao crescimento (HARR, 2002). Entretanto, CAMPBELL (2004) relaciona que podem ocorrer aumentos não significativos em situações de necrose hepática induzida pela aflatoxina $\mathrm{B}_{1}$. No presente trabalho, não se verificou a possibilidade de ocorrência de tal agente na dieta para confirmar a existência de algum distúrbio hepático em aves adultas.

Quanto ao colesterol sérico, foi observado que os valores das aves jovens $\left(170,8 \pm 30,89 \mathrm{mg} \mathrm{dl}^{-1}\right)$ foram significativamente inferiores $(\mathrm{P}=0,05)$ ao das aves adultas (202,04 $\left.\pm 38,4 \mathrm{mg} \mathrm{dl}^{-1}\right)$. Embora essa diferença não fosse verificada entre machos e fêmeas, a elevação dos valores nos adultos pode estar relacionada à vitelogênese e à formação de ovos nas aves adultas. HARR (2002) cita uma marcada elevação do colesterol em espécies ovíparas que pode estar relacionada à concentração elevada na vitelogênese. Além disso, o fato de as aves adultas estarem recebendo uma quantidade superior de sementes de girassol pode ter elevado os níveis de colesterol sérico. Isso foi confirmado por POLO et al. (1998), que relacionaram a hipercolesterolemia em aves à dieta com elevada quantidade de gordura.

Desequilíbrios nutricionais são os principais responsáveis pela ocorrência de distúrbios no metabolismo do cálcio e do fósforo em aves de estimação (OGLESBEE, 1998). Os valores de Ca nos filhotes $\left(10,14 \pm 3,44 \mathrm{mg} \mathrm{dl}^{-1}\right)$ foram significativamente superiores aos observados nas aves adultas (9,35 \pm $\left.0,62 \mathrm{mg} \mathrm{dl}^{-1}\right)$. Isso pode estar associado à dieta diferenciada oferecida às aves mais jovens.

Quanto à média de $\mathrm{Pi}$, foi constatado um valor significativamente superior $(\mathrm{P}=0,001)$ em aves adultas $\left(5,68 \pm 0,97 \mathrm{mg} \mathrm{dl}^{-1}\right)$ quando comparado às aves jovens $\left(4,68 \pm 0,23 \mathrm{mg} \mathrm{dl}^{-1}\right)$. Como os valores de Pi séricos flutuam mais livremente no sangue que o Ca, essa alteração pode ser explicada pela diferente dieta recebida pelos filhotes (FUDGE, 2000c) e pelo crescimento dos mesmos.

A regulação do metabolismo da glicose é semelhante a dos mamíferos, porém, ocorrem diferenças quantitativas, visto que a glicemia nas aves é superior (FUDGE, 2000c). Sob estresse, os níveis de glicose sangüínea se elevam significativamente (LUMEIJ, 1997). A diabete melito ocorre mais freqüentemente em papagaios-verdadeiros e africanos, calopsitas e tucanos (LUMEIJ, 1997; FUDGE, 2000) e normalmente está relacionada a um manejo alimentar inadequado. Para a monitoração a longo prazo da glicemia, pode-se mensurar a presença de proteínas glicosiladas no soro, como a hemoglobina glicada e a frutosamina (COPPO \& COPPO, 1997). Os dados que tratam da mensuração dos níveis de frutosamina em aves são escassos. Os poucos dados existentes estão relacionados à 
Tabela 2 - Parâmetros de bioquímica sangüínea de Araras canindé (Ara ararauna) adultos e filhotes de ambos os sexos mantidos em cativeiro comercial (Criadouro Asas do Brasil).

\begin{tabular}{|c|c|c|c|}
\hline \multirow{2}{*}{ Parâmetros bioquímicos } & \multicolumn{2}{|c|}{ Intervalo de confiança (95\%) } & \multirow{2}{*}{ Teste M-W } \\
\hline & Aves adultas $(n=24)$ & Aves filhotes $(n=12)$ & \\
\hline Ácido úrico $\left(\mathrm{mg} \mathrm{dl}^{-1}\right)$ & $2,3-3,2$ & $3,5-6,2$ & $\mathrm{P}<0,001$ \\
\hline Albumina $\left(\mathrm{g} \mathrm{dl}^{-1}\right)$ & $1,3-1,5$ & $1,5-1,7$ & $\mathrm{P}<0,001$ \\
\hline AST $\left(\mathrm{UI} \mathrm{L}^{-1}\right)$ & $111,6-130$ & $118,3-155,7$ & NS \\
\hline Cálcio (mg dl $\left.{ }^{-1}\right)$ & $9,1-9,8$ & $7,5-12,8$ & $\mathrm{P}<0,05$ \\
\hline Colesterol $\left(\mathrm{mg} \mathrm{dl}^{-1}\right)$ & $185,5-215,7$ & $150,1-191,6$ & $\mathrm{P}<0,05$ \\
\hline Fosfatase alcalina (UI L ${ }^{-1}$ ) & $223,3-362,0$ & $126,5-193,2$ & $\mathrm{P}<0,05$ \\
\hline Fósforo $\left(\mathrm{mg} \mathrm{dl}^{-1}\right)$ & $5,2-6,1$ & $4,5-4,9$ & $\mathrm{P}<0,001$ \\
\hline Frutosamina & $1,1-1,3$ & $7,0-16,6$ & $\mathrm{P}<0,0001$ \\
\hline Proteínas totais $\left(\mathrm{g} \mathrm{dl}^{-1}\right)$ & $3,5-3,8$ & $3,4-3,6$ & NS \\
\hline Uréia (mg dl $\left.{ }^{-1}\right)$ & $5,0-6,5$ & $4,5-7,4$ & NS \\
\hline
\end{tabular}

NS= não significativo, Teste M-W= teste Mann-Whitney.

determinação em frangos de corte como indicador de estresse crônico. PINHEIRO et al. (2003) constataram que frangos submetidos a estresse por restrição alimentar apresentaram elevação significativa dos valores de glicose e frutosamina séricas. Foram determinados os valores de frutosamina em todos os grupos de araras canindé, mas devido à escassez de dados, os valores não puderam ser comparados com a literatura. Foi constatada uma diferença significativa $(\mathrm{P}=0,0001)$ nos valores de frutosamina entre aves adultas $(1,19 \pm 0,18)$ e jovens $(1,18 \pm 0,67)$. Há necessidade de fazer a investigação mais precisa das relações da frutosamina com a glicose e o cortisol sangüíneos de araras mantidas em cativeiro.

\section{CONCLUSÃO}

Ao final da análise, pode-se afirmar que tanto o método de coleta quanto a técnica laboratorial utilizada foram adequadas para determinar parâmetros de bioquímica sérica. Sendo essas metodologias as mais utilizadas em nosso meio, os resultados apresentados podem ser utilizados como referência para araras canindé criadas em cativeiro no Brasil. Ainda que houvesse diferenças pontuais nos valores de aves adultas e filhotes, a dieta e a condição fisiológica das aves foram as causas mais prováveis de valores diferentes entre categorias em determinados indicadores. Os valores de frutosamina sérica não puderam indicar a presença de estresse nas aves testadas, pois ainda não há parâmetros de comparação em nosso meio.

\section{AGRADECIMENTOS}

Agradecimento especial às equipes do Criadouro Asas do Brasil e dos Laboratórios de Análises Clínicas da ULBRA e de Ictiopatologia da UPF. Os autores agradecem ao Programa Institucional Voluntário de Iniciação Científica da UPF (PIVICUPF).

\section{COMITÊ DE ÉTICA E BIOSSEGURANÇA}

O presente trabalho foi institucionalizado pela Divisão de Pesquisa da UPF e seguiu os Princípios Éticos na Experimentação Animal conforme recomenda o COBEA (Colégio Brasileiro de Experimentação Animal).

\section{REFERÊNCIAS}

CAMPBELL, T.W. Clinical chemistry of birds. In: THRALL, M.A. (Ed.). Veterinary hematology and clinical chemistry. Baltimore: Lippincott Williams \& Wilkins, 2004. p.479-492.

COLLAR, N.J. Family Psittacidae (parrots). In: DEL HOYO, J. et al. (Eds.). Handbook of the birds of the word. Barcelona: Lynx, 1997. v.4, p.280-447.

COPPO, J.A.; COPPO, N.B. Serum fructosamine: a reference interval for a heterogeneous canine population. Veterinary Research Communications, v.21, p. 471-476, 1997. Capturado em 10 out de 2005. On line. Disponível na internet http://www.springerlink.com/media/ba750ycdrg1wnmb0gadt/ contributions/h/5/8/n/h58n430r0157wx85.pdf.

GODOY, S.N. Patologia comparada de psitacídeos mantidos em cativeiro no Estado de São Paulo. 2001. 214f. Dissertação (Mestrado em Patologia Experimental Comparada) - Faculdade de Medicina Veterinária e Zootecnia, Universidade de São Paulo.

Avian blood sampling and artifact considerations. In: FUDGE, A.M. Laboratory medicine: avian and exotic pets. Philadelphia: Saunders, 2000a. p.1-8.

Avian liver and gastrointestinal testing. In: FUDGE, A.M. Laboratory medicine: avian and exotic pets. Philadelphia: Saunders, 2000b. p.47-55. 
Avian metabolic disorders. In: FUDGE, A.M. Laboratory medicine: avian and exotic pets. Philadelphia: Saunders, 2000c. p.56-60.

HARR, K.E. Clinical chemistry of companion avian species: a review. Veterinary clinical pathology, v.31. n.3. p.140151, 2002. Capturado em 01 out. de 2005. On line. Disponível na internet http://www.vetclinpathjournal.org/VOL31/ VCP3103_140-151.pdf.

IBAMA. Portaria 117 de 15 de outubro de 1997: Dispõe sobre a comercialização de animais vivos, abatidos, partes e produtos da fauna silvestre brasileira e dá outras providências. Diário Oficial da União n. 200 de 16/10/97, seção I, p.23489/490.

LUMEIJ, J.T. Avian clinical biochemistry. In: KANEKO, J.J. et al. Clinical biochemistry of domestic animals. 5.ed. San Diego, Califórnia: Academic, 1997. p.857-883.

MARTÍnEZ, F.A. Métodos de diagnóstico em psitaciformes. Capturado em 07 de abril de 2003. Disponível na internet http://www.portalveterinaria.com/ sections.php?op=viewarticle $\&$ artid $=178$.
MUNSON, L.; COOK, R.A. Monitoring investigation and surveillance of diseases in captive wildlife. Journal of Zoo and Wildlife Medicine, v.24, p.281-289, 1993.

OGLESBEE, B.L. Distúrbios dos animais de estimação aviários e exóticos. In: BICHARD, S.J.; SHERDING, R.G. Manual Saunders: clínica de pequenos animais. São Paulo: Roca, 1998. p.1397-1404.

PHALEN, D.N. Avian renal disorders. In: FUDGE, A.M. Laboratory medicine: avian and exotic pets. Philadelphia: Saunders, 2000. p.60-68.

PINHEIRO, C.C. et al. Indicadores sangüíneos de estresse por calor e restrição alimentar em frangos de corte. In: SALÃO DE INICIAÇÃO CIENTÍFICA DA UFRGS, 15., 2003, Porto Alegre. Livro de Resumos... Porto Alegre: Pró-reitoria de Pesquisa, 2003. p.163.

POLO, F.J. et al. Hematologic and plasma chemistry values in captive psittacine birds. Avian disease, v.42, p.523-535, 1998.

SICK, H. Ornitologia brasileira. Rio de Janeiro: Nova Fronteira, 1997. 912p. 